\title{
1 Interactions of Staphylococcus aureus with Ultrasoft Hydrogel Biomaterials
}

2 Yi Wang ${ }^{1}$, Allan Guan ${ }^{2}$, Irada Isayeva ${ }^{1}$, Katherine Vorvolakos ${ }^{1}$, Srilekha Das ${ }^{1}$, Zhenyu Li ${ }^{2}$ and K. Scott

3 Phillips ${ }^{1}$

$4{ }^{1}$ United States Food and Drug Administration, Office of Medical Products and Tobacco, Center for Devices and

5 Radiological Health, Office of Science and Engineering Laboratories, Division of Biology, Chemistry and Materials

6 Science, 10903 New Hampshire Ave, Silver Spring, MD 20993, USA

$7 \quad{ }^{2}$ Department of Biomedical Engineering, The George Washington University, Science and Engineering Hall, 800

8 22nd Street NW, Washington, DC 20052, USA

9 Abstract

Ultrasoft biomaterials-ultrasoft polymers, gels, and human soft tissues with an elastic modulus less than $\sim 100 \mathrm{kPa}$-are increasingly used in medical devices. While bacterial interactions (adhesion and biofilm formation) have been extensively studied on stiffer materials, little is known about how bacteria colonize ultrasoft materials as a nidus for infection. The goal of this work was to determine how material properties of ultrasoft hydrogels used for dermal fillers might affect pathogenesis of associated infections. We first synthesized a range of polyacrylamide hydrogels (PAAm) with moduli similar to clinically used dermal fillers and characterized the rheological, morphological and porous properties. We then developed a novel microfabricated insert to contain the PAAm in a flow system for quantification of bacterial adhesion and biofilm formation. The rate of adhesion and numbers of adherent $S$. aureus on the surface of PAAm both decreased as the modulus increased. Adhesion was reduced by 4 logs (from $93 \times 10^{4} / \mathrm{cm}^{2}$ to $0.083 \times 10^{4} / \mathrm{cm}^{2}$ ) with increasing modulus (from 17Pa to 654Pa). However, the number of bacteria in the bulk was the highest within the stiffest gels. This trend was further amplified in subsequent biofilm studies, where interfacial coverage of biofilm decreased with the modulus while the fraction of biofilm in the bulk was the highest within the stiffest gel. The results show significant differences in bacterial colonization of PAAm based on material properties, and reveal how the injection process may unexpectedly create discontinuities that provide a microenvironmental niche for bacterial colonization.

\section{Introduction}

Ultrasoft biomaterials - ultrasoft polymers, gels with an elastic modulus less than $\sim 100 \mathrm{kPa}(1)(2)-$ can be precisely tailored to match the non-linear mechanical properties of a biological matrix such as 
human soft tissues, enabling their use in diverse medical products such as injectable implants, cell scaffolds in tissue engineering and drug releasing vehicles. Among these biomaterials, ultrasoft hydrogels are distinguished from soft hydrogels (100 kPa 1 GPa)(3) because they can be placed in the body by injection through a narrow bore needle. This unique property is the basis for their role in the rapidly growing use of dermal fillers to augment skin tissue (4). Partial failure of skin elasticity can be caused by factors such as sun exposure, free radicals and trauma. Dermal fillers are tailored to match the elasticity of cutaneous tissue that is normally provided by collagen and elastin fibers. The optimal elasticity varies depending on the anatomic location and depth of placement. Materials with lower elastic modulus are generally matched to delicate tissue structures and may cause less pain when injected whereas materials with a higher elastic modulus may be used in deeper injections or for bulkier or longer-lasting effects.

While injection of filler materials is not subject to the same infection risks as open surgery, injected materials share in common with implanted and indwelling medical device materials (Figure 1) the potential for associated infection with persistent, antibiotic resistant organisms (5)(6). The time of onset for symptoms of infection can vary from shortly after injection to years later (7). Although adverse event rates for some dermal fillers can be as high as $20 \%(8)$, it is not known how many are related to bacterial colonization vs. aseptic origin (allergies, inflammatory response, etc.). The use of molecular techniques such as PCR and FISH has increasingly shown a link between colonization and adverse events. In one clinical case-control study, aggregates of skin bacteria such as Staphylococcus epidermidis and Propionibacterium acnes were identified in 53 out of 54 patients with severe adverse events due to filler injection, while none were found in 24 control subjects (with dermal filler injection but no adverse reactions) (9). Longer lasting materials (semi-permanent or permanent)(10) and some injection locations (11)(12) have also been associated with higher risk of infection. Treatment of these materials often requires a combination of surgery and prolonged antibiotic use, at significant cost and pain to patients (10)(13)(5).

To develop improved dermal fillers, it is important to understand the pathogenesis of infections associated with ultrasoft biomaterials. In contrast to the extensive knowledge about how bacteria can colonize hard and soft materials to become a persistent source of bioburden (14)(15), less is known about bacterial interactions with ultrasoft materials. A recent in vitro study showed that P.aeruginosa, S.epidermidis, and P.acnes formed robust biofilms in several dermal filler materials (hyaluronic acid gel, calcium hydroxyl apatite microspheres in carrier gel, and polyacrylamide hydrogel) (16). P.aeruginosa biofilm in polyacrylamide gel was not susceptible to tobramycin at concentrations 200x the normal 
minimum inhibitory concentration (MIC) obtained from disc diffusion testing (17). The same authors also showed that as few as 40 bacteria in

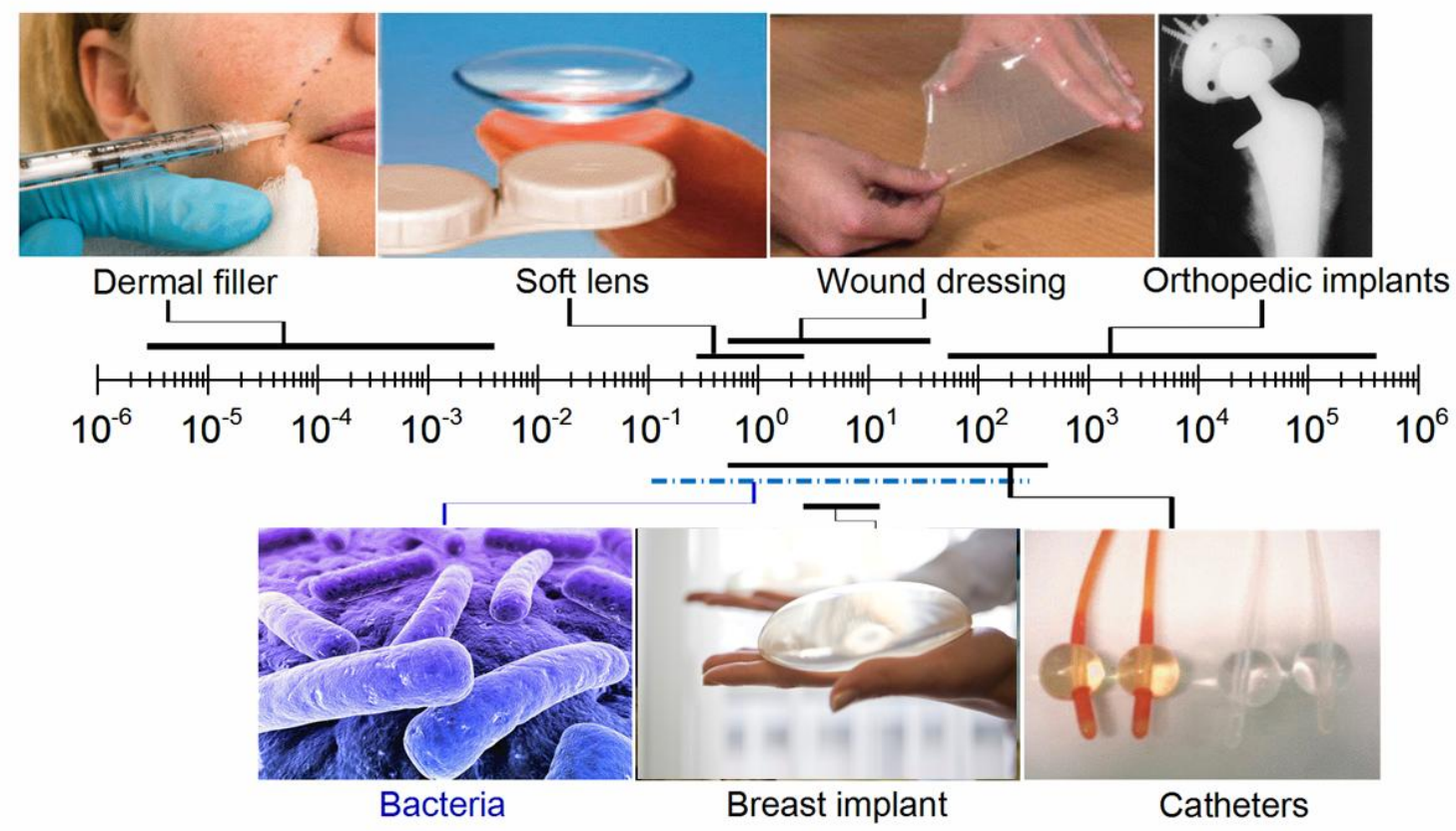

Figure 1. Stiffness (Young's modulus, MPa) of some medical devices that are colonized by bacteria. In black print, from top to bottom, left to right: Dermal filler (0.02 - $3 \mathrm{kPa}$ )(18); Soft contact lens (0.2 - $1.5 \mathrm{MPa}$ )(19); Wound dressing (0.5-25 MPa) (20)(21); Orthopedic implant (5 - $300 \mathrm{GPa}$ )(22); Silicone gel-filled breast implant shells (2$12 \mathrm{MPa}$ )(23); Catheters: $\mathbf{0 . 4}$ - $300 \mathrm{MPa}$ (24)(25); For reference, bacteria (blue print, bottom left) have a stiffness of $0.1-200 \mathrm{MPa}$ (26); The modulus of dermal fillers was estimated using the classical relation between the Young's modulus and the shear modulus- E=3G) (27).

filler materials could cause infection in a mouse model. The outcome was strongly material dependent.

Ultrasoft hydrogels have fundamental differences with stiffer materials that could potentially impact mechanisms of bacterial pathogenesis. The adhesion mechanisms may be different. Bacterial adhesion on stiffer materials relies on both chemical interactions (van der Waals, electrostatic and hydrophobic forces) and surface mechanical clues (roughness, patterns). Nevertheless, mechanical (viscoelastic) properties may play a more dominant role in driving the interactions with ultrasoft hydrogels because of the high water content at the gel-medium interface. In contrast to the discrete solid-liquid interface of stiff materials, the topography of loosely crosslinked hydrogels presents a more gradual transition(14). In addition, colonization may be impacted by the shift from a planar two-dimensional 
81 surface to a porous three-dimensional matrix. Many eukaryotic cells have different growth dynamics in a

82 three-dimensional matrix when compared with planar surfaces (28) and bacteria may follow similar environmental cues. Finally, ultrasoft hydrogels are less homogeneous than stiffer materials(29).

84 Mechanical processes such as injection can further enhance this non-uniformity, resulting in unique 85 spatial constraints and microenvironments - that may have unexpected impact on biofilm growth 86 dynamics. The porous and heterogeneous structure may present an ecological niche for bacteria while 87 hindering the response of larger immune cells.

88 The goal of this work was to determine how the properties of ultrasoft hydrogels affect bacterial 89 adhesion and early-stage biofilm growth, two of the earliest stages in the bacterial pathogenesis of 90 dermal filler associated infections. The work was divided into four stages: (i) We synthesized 91 polyacrylamide hydrogels (PAAm) with elastic moduli similar to the range used for commercial dermal 92 fillers, and characterized the rheological, morphological and porous properties. (ii) We developed a 93 strategy to test bacterial adhesion and biofilm formation in PAAm using an aqueous flow cell with 94 quantifiable shear stress. Due to the buoyant and fluid-like behavior of the gels, a novel microfabricated 95 insert was developed to hold them in place for testing. The insert was integrated into a conventional 96 flow system for studying adhesion and biofilm formation using confocal microscopy. (iii) The interaction 97 of green fluorescent protein (GFP)-tagged staphylococci with the gels was quantified under flow, and (iv) 98 biofilm formation was evaluated.

\section{2. Materials and methods}

2.1 Preparation and characterization of Polyacrylamide hydrogels (PAAm)

PAAm synthesis Polyacrylamide hydrogels (PAAm) were prepared by copolymerization/crosslinking 103 of acrylamide (AAm) monomer with bis-acrylamide (bisAM, N, $\mathrm{N}^{\prime}$-Methylenebisacrylamide). The polymerization/crosslinking procedure was adapted from methods described to produce a soft tissue filler endoprosthesis (30). AAm monomer ( $\geq 99 \%$, Sigma-Aldrich) and bisAM crosslinker ( $\geq 95 \%$, Fisher Scientific) were received and dissolved in deionized (DI) water to make $40 \mathrm{wt} \%$ and $2 \mathrm{wt} \%$ solutions. Water was used instead of saline to facilitate comparison with previous work and minimize experimental challenges associated with precipitation. Ammonium persulfate (APS) was used as a freeradical initiator and tetramethylethylenediamine (TEMED) was used as an accelerator/co-initiator. AAm and BisAM concentrations (monomer concentration, $\% \mathrm{~T}$ ) were fixed at $5 \%(\mathrm{w} / \mathrm{v})$ for all gel preparations. Molar ratios of AAm to bisAM in the polymerization were adjusted to 100:1, 300:1, 500:1 and 700:1, which corresponding to $2.13 \%, 0.718 \%, 0.432 \%$ and $0.309 \%$ for the proportion of cross-linker to the 
monomer mixture $(\% \mathrm{C}, \mathrm{w} / \mathrm{w})$. The molar mass of APS and TEMED were proportional to the total molar mass of (AAm + bisAM) (1:300 and 1:250, respectively). AAm, bisAAm, and TEMED were mixed as solution A, while APS was mixed with DI water as solution B. Both solutions were sterilized with a $0.22 \mu \mathrm{m}$ filter system (Corning, NY, USA), and then degassed with nitrogen for 20 seconds. The two 116 solutions were kept in a $45^{\circ} \mathrm{C}$ water bath with mixing, and then cast into sterile 24 -well plates. Polymerization was carried out for $2 \mathrm{~h}$ at room temperature. The gel was removed from the mold and residual monomers were extracted in sterile water at room temperature for 14 days by changing the water twice daily, and then stored hydrated at $4^{\circ} \mathrm{C}$.

Swelling of PAAm For swelling measurements, PAAm samples were blotted with filter paper (to remove surface water) and weighed to obtain the swollen weight $\left(W_{S}\right)$ ( $n=5$ for each crosslinking ratio). They were then dried in a temperature and humidity chamber (Espec North America, MI) at $40{ }^{\circ} \mathrm{C}$ set at $0 \%$ humidity for 3 days to obtain the dry weight $\left(W_{d}\right)$. The weight swelling ratio $\left(Q_{m}\right)$ was determined as $Q_{m}=\frac{W_{s}}{W_{d}}$. The polymer volume fraction in the swollen gel $\left(v_{2 m}\right)$ was defined as the ratio of the polymer volume $\left(V_{p}\right)$ to the swollen gel volume $\left(V_{g}\right)$ and is also a reciprocal of the volumetric swelling ratio $Q_{v}$. They can be related to the densities of the solvent $\left(\rho_{s}\right)$ and polymer $\left(\rho_{p}\right)$, and $Q_{m}$ as described by Eq.1:

$$
v_{2 m}=\frac{V_{p}}{V_{g}}=\frac{1}{Q_{v}}=\frac{1 / \rho_{p}}{Q_{m} / \rho_{s}+1 / \rho_{p}}
$$

where $\rho_{p}$ is $1.13 \mathrm{~g} / \mathrm{cm}^{3}$ for AAm and $\rho_{s}$ is $0.997 \mathrm{~g} / \mathrm{mL}$ for water at $25 \circ \mathrm{C}(31)$.

Structure evaluation Generally, three parameters are most important in the quantitative determination of the microstructure of an idealized hydrogels: the polymer volume fraction in the swollen state, $v_{2 m}$; the average molecular weight between crosslinks, $\bar{M}_{c}$; and the pore size $\zeta$, which indicates the maximum size of solutes that can pass through the network. Equilibrium-swelling theory is applied to describe these parameters by utilizing the Flory and Rehner equation (32)(33), assuming a perfect network,

$$
\bar{M}_{C}=-\frac{v_{1}}{\bar{v}} \times \frac{\left(v_{2 m}{ }^{\left.\frac{1}{3}-\frac{v_{2 m}}{2}\right)}\right.}{\ln \left(1-v_{2 m}\right)+v_{2 m}+\chi_{1} v_{2 m}{ }^{2}}
$$

Where, 
$\bar{M}_{C}$ is the number average molecular weight of the polymer between crosslinks

$v_{1}$ is the molar volume of the solvent, $18.07 \mathrm{~cm}^{3} / \mathrm{mol}$ for water at room temperature

$\bar{v}$ is the specific volume of the polymer, which is the reciprocal of polymer density $\frac{1}{\rho_{p}}=\frac{1}{1.13 \mathrm{~g} / \mathrm{cm}^{3}}$

$\chi_{1}$ is the Flory-Huggins interaction parameter between solvent and polymer ( 0.48 for PAAm/water) The hydrogel pore size $\zeta$ was calculated using the following equation:

$$
\zeta=v_{2, s}{ }^{-\frac{1}{3}}\left(\overline{r_{0}^{2}}\right)^{\frac{1}{2}}
$$

Here, $\left(\overline{r_{0}^{2}}\right)^{\frac{1}{2}}$ is the root-mean -squared end-to -end distance of network chains between two adjacent crosslinks in the unperturbed state. It can be determined by (34):

$$
\left(\overline{r_{0}^{2}}\right)^{\frac{1}{2}}=l\left(C_{n} N\right)^{1 / 2}=l\left(C_{n} \frac{2 \overline{M_{c}}}{M_{r}}\right)^{1 / 2}
$$

Where $C_{n}$ is the polymer rigidity factor ( 8.8 for PAAm) (35), $l$ is the bond length along the polymer backbone (1.54 $\AA$, corresponding to the $\mathrm{C}-\mathrm{C}$ bond length), $\mathrm{N}$ is the number of bonds between adjacent crosslinks and $M_{r}$ is the molecular weight of the repeat unit, taken as a weighted average of the molecular weight of the monomers $(A A m=71.08 \mathrm{~g} / \mathrm{mol})$.

Rheological characterization Rheological characterization was performed on a rotational rheometer (AR-G2, TA instruments, UK) with a $20 \mathrm{~mm}$ diameter stainless steel cone and plate geometry head, at 37 ${ }^{\circ} \mathrm{C}$ and $100 \%$ relative humidity $(\mathrm{RH})$. The cylindrical PAAm samples $(n=15)$ were $\sim 15 \mathrm{~mm}$ diameter and $1.2 \mathrm{~mm}$ thick. Measurements were performed within $0.1-100 \mathrm{~Hz}$ at a $5 \%$ constant deformation to obtain G' (shear storage modulus) and G" (shear loss modulus).

2.2 Morphological examination

Laser scanning confocal microscope (CLSM): Imaging of PAAm surfaces was performed with a Leica SP8 CLSM (Leica Microsystems, Germany). PAAm were injected into reservoirs of a flow-cell insert (See 2.3 below). The chamber was then filled with DI water. PAAm were allowed to reach equilibrium for $30 \mathrm{~min}$ before imaging. Reflectance images were obtained with a $514 \mathrm{~nm}$ laser source by filtering reflected light with an acousto-optical beam splitter (510-540nm window) and capturing with a hybrid photomultiplier tube/avalanche photodiode detector (Leica HyD). 
Scanning electron microscopy PAAm were prepared for scanning electron microscopy (SEM) by progressively dehydrating in a series of ethanol (200proof, 50\%, 75\%, 95\% and three times in 100\%, $10 \mathrm{~min}$ at each concentration). The samples were subsequently critical point dried (AutoSamdri-815, Tousimis Research Corp., Rockville, MD), sputter coated with gold/palladium (10 nm, EMS150T, EMS, PA), and imaged using a SEM (JSM-6390 LV, JEOL, MA) at a voltage of $2 \mathrm{kv}$.

\subsection{Fabrication and assembly of multilayer insert}

Insert microfabrication A multi-layer insert (Figure 4) was microfabricated to hold ultrasoft materials 172 in a flow chamber during the investigation of bacterial interactions. Master molds were made with SU-8 1732150 (Microchem, Newton, MA) on 3" Si wafers (Wafer World Inc., West Palm Beach, FL) using 174 photolithography (NanoCenter FabLab, University of Maryland). Two layers were fabricated separately 175 by casting PDMS replicas from the masters and aligned when semi-cured to match the meshes over the 176 circular reservoirs. The bottom layer (PDMS L1) was $800 \mu \mathrm{m}$ thick and contains 4 reservoirs of $3 \mathrm{~mm}$ 177 diameter, and separated by $2 \mathrm{~mm}$. The top layer (PDMS L2) is a $25 \mu \mathrm{m}$ thick sheet with $4 \times 4$ arrays of 178 circular openings (500 $\mu \mathrm{m}$ diameter) with $150 \mu \mathrm{m}$ edge-to-edge distance. The top layer was partially 179 cured and then aligned with the bottom layer so that the $4 \times 4$ arrays were centered over the 4 large 180 reservoirs. The two layers were then irreversibly bonded at $75^{\circ} \mathrm{C}$ to fully cure. The assembly surface was 181 plasma oxidized and attached to a coverslip (\#0, Ted Pella Inc., Redding, CA). The assembly was then 182 integrated into a standard biofilm microscopy observation flow system (BioSurface Technologies Corp., 183 Bozemen, MT). Four reservoirs with the above described assemblies were fixed to a $24 \times 60 \mathrm{~mm}$ 184 coverslip.

PAAm integration with insert After washing and swelling, PAAm were aseptically filled into sterile syringes. Needles (25 gauge) were used to penetrate the PDMS layer and transfer the PAAm into the reservoirs. PDMS self-seals after removal of the needle. To develop a repeatable procedure, PAAm were filled to the same level up to the mesh layer with a 3D Eyepiece-less Inspection Microscope (Mantis Elite, Vision Engineering Inc.). Up to 4 different types of gels could be tested simultaneously in the same experiment.

\subsection{Bacterial culture and interactions}

Bacterial preparation Green fluorescent protein tagged Staphylococcus aureus (S.aureus) AH2547 were provided by Dr. Alexander Horswill (Department of Biology, The University of lowa, lowa City, IA, USA). A colony of $S$. aureus was removed from the source agar plate using an inoculating loop. The 


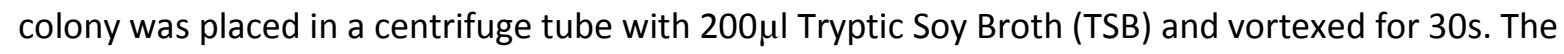
solution $(50 \mu \mathrm{l})$ was pipetted into a petri dish along with $20 \mathrm{ml}$ of TSB and incubated at $37^{\circ} \mathrm{C}$ for $16-18 \mathrm{~h}$ Culture medium was then removed from the petri dish and rinsed with PBS three times. PBS (3 ml) was added to the washed dish and a cell scraper was used to remove the film of S.aureus from the bottom of the dish. The solution was pipetted into a centrifuge tube and vortexed for $30 \mathrm{~s}$, and followed by $5 \mathrm{~min}$ sonication. Using a syringe the solution was pushed through a $5 \mu \mathrm{m}$ filter to remove large clumps of S.aureus to get the single or double cell solution. The concentration was determined to be $10^{9} \mathrm{cfu} / \mathrm{ml}$ by plating on agar plates (trypticase soy agar, with $5 \%$ sheep blood, Becton, Dickinson and Company).The solution was then re-suspended to a concentration of $10^{7} \mathrm{cfu} / \mathrm{ml}$ in PBS.

Bacterial adhesion PAAm in the reservoirs of the insert were settled for $30 \mathrm{~min}$ to reach equilibrium. The $S$. aureus suspension was perfused through the chamber (shear rate of $0.2 \mathrm{~s}^{-1}$, corresponding to Reynolds number of 0.26 ) for $2.5 \mathrm{~h}$ at room temperature. After S.aureus deposition, sterile PBS was injected $\left(10 \mathrm{~s}^{-1}\right)$ for $30 \mathrm{~min}$ to remove non-adhering S.aureus from the chamber and from the tubing system. Bacteria-gel interactions were studied in a microscopic observation flow cell and imaged in situ with CLSM (485nm excitation/535nm emission). Three-dimensional (500 $\mu \mathrm{m}$ depth) scans were taken every 30min during the deposition and after the PBS rinse. S. aureus adhesion was divided into interface and bulk components. Density at the PAAm surface (bacteria/ $\mathrm{cm}^{2}$ ) was obtained by counting S.aureus within $50 \mu \mathrm{m}$ of the PAAm gel/water interface (hereafter referred to as "the interface" unless otherwise noted).

This number was obtained by evaluating (for all of the PAAm samples) the local minima in emission as a function of distance from the interface. In all of the samples, emission dropped off rapidly at $50 \mu \mathrm{m}$ or less from the interface. The role of surface roughness and out of plane emission may also play a role and can be estimated from the much stiffer PDMS control where emission dropped off at 10-20 $\mathrm{mm}$ from the interface. The number of S.aureus at the PAAm interface was normalized to the geometric area of the control surface $(200 \mu \mathrm{m} \times 200 \mu \mathrm{m})$. S.aureus in the remaining $450 \mu \mathrm{m}$ of the gel depth were counted as being inside the bulk PAAm and were quantified by volume (number $/ \mathrm{mL}$ ). All experiments were replicated in triplicate with three independent S.aureus cultures.

Biofilm formation and quantification For the assessment of initial biofilm formation, sterile TSB (1:3 dilution) was flowed through the system at a low shear rate $\left(0.01 \mathrm{~s}^{-1}\right)$ for $24 \mathrm{~h}$. A thermoelectric heating element was used to maintain the chamber temperature at $37^{\circ} \mathrm{C}$. After $24 \mathrm{~h}$, another $30 \mathrm{~min}$ of PBS 
rinsing $\left(10 \mathrm{~s}^{-1}\right)$ was performed. Experiments were performed in triplicate with independent S.aureus cultures. The four PAAm types were placed in different reservoirs on the same insert. CLSM imaging was performed at three of the $500 \mu \mathrm{m}$ mesh openings for each reservoir. The locations were chosen at the center of reservoir to avoid edge effects. CLSM images were collected with $485 \mathrm{~nm}$ excitation/535nm emission. Simulated fluorescence projections through the biofilm were generated using the Leica LAS software. Quantitative characterization of bacterial distribution in the image stacks was carried out with Fiji (ImageJ) (36) and COMSTAT software (37). The interfacial coverage of PAAm was manually calculated using the operation:

$$
\text { Interfacial Coverage }(\%)=\frac{\text { Interface Integrated Intensity }}{\text { PDMS Surface Integrated Intensity }} \times 100 \%
$$

The fraction of all bacteria in the PAAm that was in the bulk (not associated with the interface) was obtained with the aid of software analysis using the operation:

$$
\text { Bulk Fraction }(\%)=\frac{\text { Total Bacterial Volume-Volume of Microcolonies at Substratum }}{\text { Total Bacterial Volume }} \times 100 \%
$$

The Bulk Fraction represents the fraction of biofilm deeper than $50 \mu \mathrm{m}$ in the PAAm (biofilm in the bulk material that is not connected with biofilm at interface). It was calculated from the bacterial volume in the whole scanned cube (Total Bacterial Volume, $200 \mu \mathrm{m} \times 200 \mu \mathrm{m} \times 500 \mu \mathrm{m}$ ) and the volume of bacteria at interface (Volume of Microcolonies at Substratum, $200 \mu \mathrm{m} \times 200 \mu \mathrm{m} \times 50 \mu \mathrm{m})$. Total Bacterial Volume is calculated by Biomass $\times$ area $(200 \mu \mathrm{m} \times 200 \mu \mathrm{m})$, where Biomass was acquired using a COMSTAT function and is defined as the volume of all voxels that contain bacteria divided by the area. Volume of Microcolonies at Substratum was also acquired using a COMSTAT function and is the volume of all connected bacteria at the interface $(50 \mu \mathrm{m})$.

\subsection{Statistical analysis}

S.aureus adhesion and biofilm formation to the four PAAm hydrogels in the ultrasoft materials insert/parallel flow chamber were tested with three independent S.aureus cultures. Data are represented in graphs and text as a mean with its standard deviation. For statistical analysis of adhesion and biofilm formation data, ANOVA was employed with Tukey's HSD post-hoc test and a $P$-value $<0.05$ was considered to be significant. 


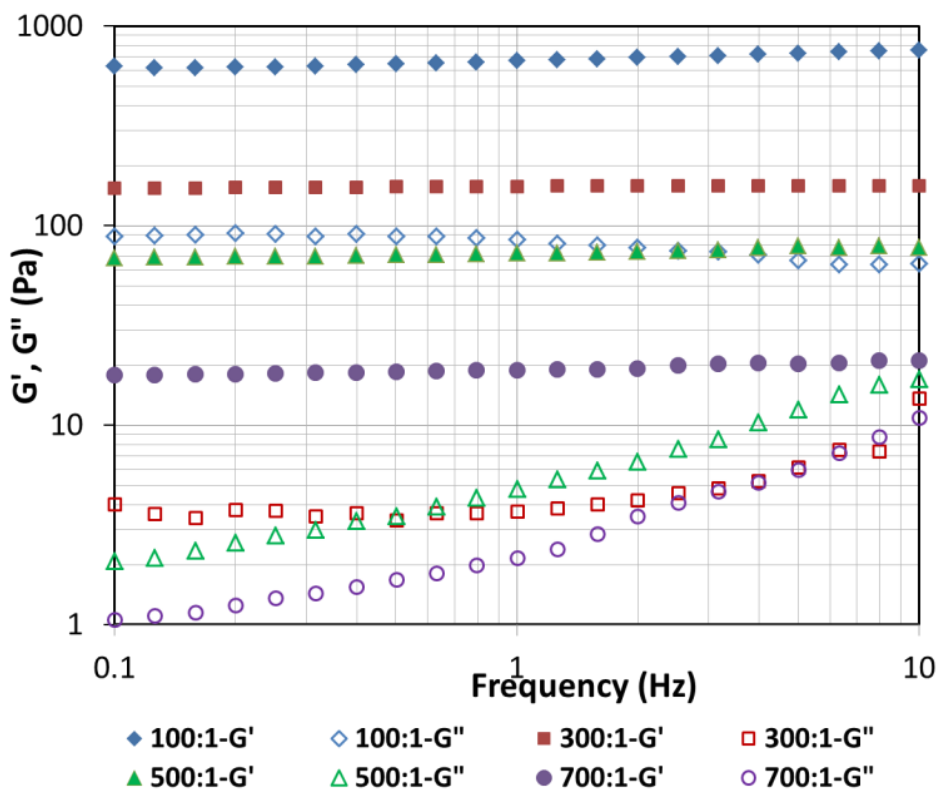

Figure 2. Elastic (G') and viscous (G") modulus for PAAm with crosslinking ratio [AAm]:[BisAAm].3. Results and discussion

$254 \quad 3.1$ Effects of crosslinking on PAAm mechanical properties and microstructure

255 PAAm was used as a model ultrasoft material due to the well-established chemical crosslinking 256 method, tunability of hydrogel properties, and its use in some dermal filler products (Although PAAm 257 dermal fillers are not approved in the U.S., many PAAm formulations have been used in aesthetic plastic 258 and reconstructive surgeries in other countries) (13). By varying the monomer (AAm) to crosslinker 259 (BisAM) molar ratio, we prepared four PAAm (PAAm-100, PAAm-300, PAAm-500 and PAAm-700) with 260 elastic modulus $\left(G^{\prime}\right)$ range comparable to those reported for commercially available hydrogel filler 261 materials (18).The deformability and fluidity of the PAAm was characterized with dynamic rheological 262 measurements (Figure 2). In common with other hydrogels, $\mathrm{G}^{\prime}$ as a measure of the energy stored by the 263 gel during deformation -was nearly independent of frequency. The viscous modulus ( $\left.G^{\prime \prime}\right)$ represents the 264 energy loss on shear deformation. When $G^{\prime}$ is much higher than $G^{\prime \prime}$, the elastic behavior (i.e. gel-like) 265 under low shear stress is dominant over the viscous (i.e. liquid-like) behavior. For the less crosslinked 266 PAAm-500 and PAAm-700, G' is frequency dependent within the test range, meaning that they flow 267 with less applied force. In all four PAAm, the elastic character dominates the rheological behavior 268 despite the gel being mostly liquid. 


\begin{tabular}{|c|c|c|c|c|}
\hline $\begin{array}{l}{[\mathrm{AAm}]} \\
/[\text { bisAM] }\end{array}$ & Short name & $\begin{array}{l}G^{\prime}[\mathrm{Pa}] \\
(0.1 \mathrm{~Hz})\end{array}$ & $\begin{array}{l}\text { Swelling } \\
\text { ratio }(\mathrm{Qm})\end{array}$ & $\begin{array}{l}\text { Pore size } \\
(\zeta, \mathrm{nm})\end{array}$ \\
\hline $100: 1$ & PAAm-100 & $654 \pm 58$ & $29 \pm 9$ & $117 \pm 48$ \\
\hline $300: 1$ & PAAm-300 & $164 \pm 33$ & $45 \pm 9$ & $208 \pm 54$ \\
\hline 500:1 & PAAm-500 & $72 \pm 16$ & $57 \pm 12$ & $287 \pm 76$ \\
\hline $700: 1$ & PAAm-700 & $17 \pm 5$ & $82 \pm 17$ & $446 \pm 114$ \\
\hline
\end{tabular}

Table 1. Mechanical and structural properties of PAAm.

The $\mathrm{G}^{\prime}$ values were compared at $0.1 \mathrm{~Hz}$ (Table 1 ) because this frequency is physiologically 272 relevant (38). Synthesized PAAm were found to have $\mathrm{G}^{\prime}(0.1 \mathrm{~Hz})$, ranging from 17 to $654 \mathrm{~Pa}$ (Table 1$)$. As 273 expected, a decreasing degree of crosslinking (higher AAm: bisAM ratio) leads to a smaller G' value. Also, 274 the less crosslinking present in a hydrogel, the more it can expand to take on additional water. These 275 results are consistent with the equilibrium swelling ratio $\left(Q_{m}\right)$ for PAAm, which was used to calculate 276 the pore size $(\zeta)$ of the PAAm gels. $\zeta$ of $117-446 \mathrm{~nm}$ are comparable to the values reported in the 277 literature(39)(40) for PAAm with similar polymer and relative bisAM concentrations. The pore size 278 calculation was based on the classical theory of Flory and Rehner. They predict that for a neutral gel, if 279 the three-dimensional networks was perfect, the chain dimensions in the swollen gel are equal to its 280 dimensions in free solution(32)(41). Although the normal Staphylococci cells $(\sim 0.6-1 \mu \mathrm{m})(42)$ are larger 281 than the pore size of model gels in our system, we expect that imperfections (free chain ends, loops, and 282 entanglements etc.), as in most practical gels with low crosslinking, can increase the interaction 283 between PAAm and bacteria.
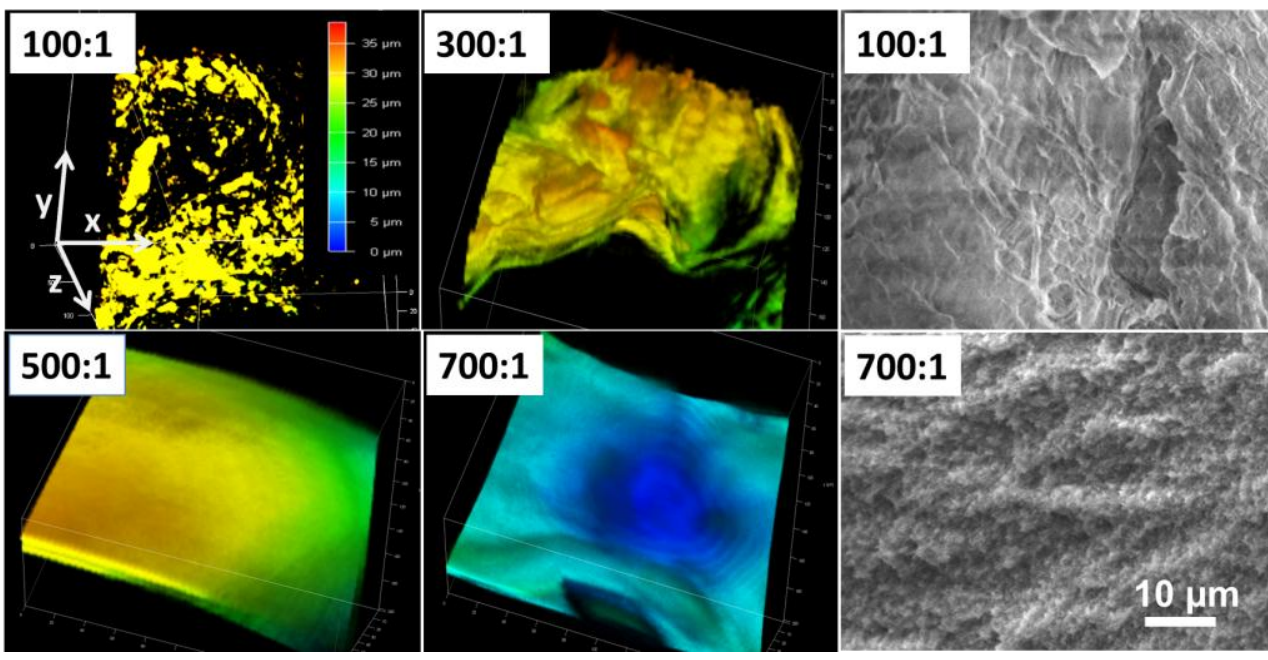
Figure 3. Left: Reflectance images of PAAm hydrogel interface showing interfacial topography $(200 \mu \mathrm{m} \times 200 \mu \mathrm{m} \times$ $35 \mu \mathrm{m}(\mathrm{x} \times \mathrm{y} \times \mathrm{z}))$. Color scale (top left image) represents z-depth. Right: SEM images of PAAm hydrogels showing topography of the cross-section.

3.2 Effects of crosslinking on PAAm interfacial topography and morphology

Material surface topography, defined by morphology and roughness, is known to play an important role in bacterial interactions (14)(43). The undulations that form on polymer gels are more dynamic than topography on hard surfaces, making them more challenging to characterize(29). This has necessitated the use of unconventional strategies such as imaging fluorescent beads that collect at the gel-water interface (44). In this work, we found that reflectance imaging with a coherent illumination source was helpful for characterizing the PAAm topography (Figure 3). Contrast in the reflectance images was a function of the difference in refractive index between the gel and water (45). Reflected light images showing the interfacial topography and morphology of the gels exhibited distinct differences for samples from each of the four different crosslinking ratios. The most crosslinked PAAm100 had a rough, discontinuous structure ( $\sim 35 \mu \mathrm{m}$ vertical irregularities), that appeared to be precipitous ledges with no transition features. PAAm-700 were more uniform with the smoothest interface ( $10 \mu \mathrm{m}$ verticale height difference). The PAAm-300 and PAAm-500 also had vertical peaks up to $\sim 35 \mu \mathrm{m}$, but these peaks were part of transitional structures. The PAAm-300 and PAAm-500 morphologies appeared to be at intermediate steps that spanned the gap between the extremes of PAAm-100 and PAAm-700. Interfacial features of PAAm cross-sections were also studied with scanning electron microscopy (SEM). Similar to the reflectance imaging, gels with higher crosslinking (PAAm-100) are more discontinuous than gels of lower crosslinking (PAAm-700). For stiffer biomaterial surfaces such as orthopedic implants, it is reported that irregularities (scratches, grooves and fissures etc.) promote bacterial adhesion and biofilm formation compared to smooth surfaces(46)(47), especially when the scale of irregularities is greater than the size of bacteria. It is hypothesized that the greater surface contact area and roughened structure provides a niche area that afford opportunity for colonization. Bacterial adhesion on soft surfaces, such as hydrogel contact lenses is also significantly influenced by surface morphology(48)(49). The characterization reported here demonstrates that within the ultrasoft regime, a small change in hydrogel crosslinking density, and its corresponding effect on viscoelastic properties, can produce significant changes in both the interface morphology and bulk structure. To our knowledge, there are no studies of how the morphology of an ultrasoft surface/interface affects bacterial adhesion and biofilm formation. 


\section{Figure 4. Schematic of flow chamber: PDMS-L1 (light gray): bulk reservoirs ( $3 \mathrm{~mm}$ diameter) hold hydrogel} material (blue); PDMS-L2 (dark gray): circular mesh openings (500 $\mu \mathrm{m}$ diameter) retain hydrogel by surface tension while allowing for bacterial interactions; Area of enhanced detail: Staphylococci (orange) interact with PAAm interface.

3.3 Microfabrication of multilayer insert for studying S.aureus interactions with ultrasoft hydrogels

Real-time assessment of S.aureus interactions and subsequent biofilm formation at the solid-liquid interface has been extensively studied in parallel flow chamber (50)(51). These systems generate a welldefined hydrodynamic profile which contributes to a better understanding of the role of surface properties (surface energy, roughness, topography, chemistry, etc.). Ultrasoft hydrogels present a challenge because of their high water content and buoyancy, making it difficult to secure them in a flow cell in a way that is amenable to reproducible studies. Initially we tried to retain hydrogels in a $3 \mathrm{~mm}$ recessed reservoir, an approach that has been used successfully for stiffer material samples. However, most of the hydrogels would float out of the recess and travel downstream until they blocked the outlet ports and tubing. To solve this challenge, a two-layer PDMS mesh insert was developed using rapid prototyping with soft lithography (Figure 4). The mesh size was optimized to hold samples of ultrasoft hydrogels in place while providing sufficient surface area for bacterial deposition and microscopic observation. The area of the mesh openings $\left(196,000 \mu \mathrm{m}^{2}\right)$ was sufficiently large so that bacteria deposited without accumulating vertically at the interface. The optimal capacity of the bulk reservoirs $(6 \mu \mathrm{L})$ is a compromise related to the diameter of the opening: too small of an opening would be difficult 

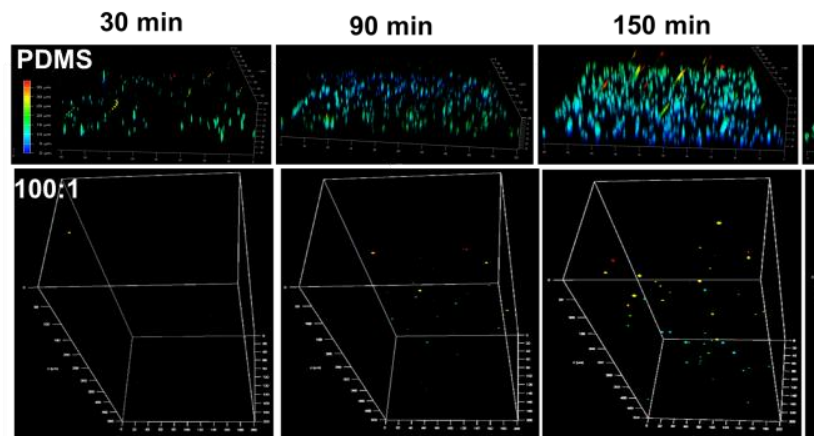
After $\mathbf{3 0}$ min wash
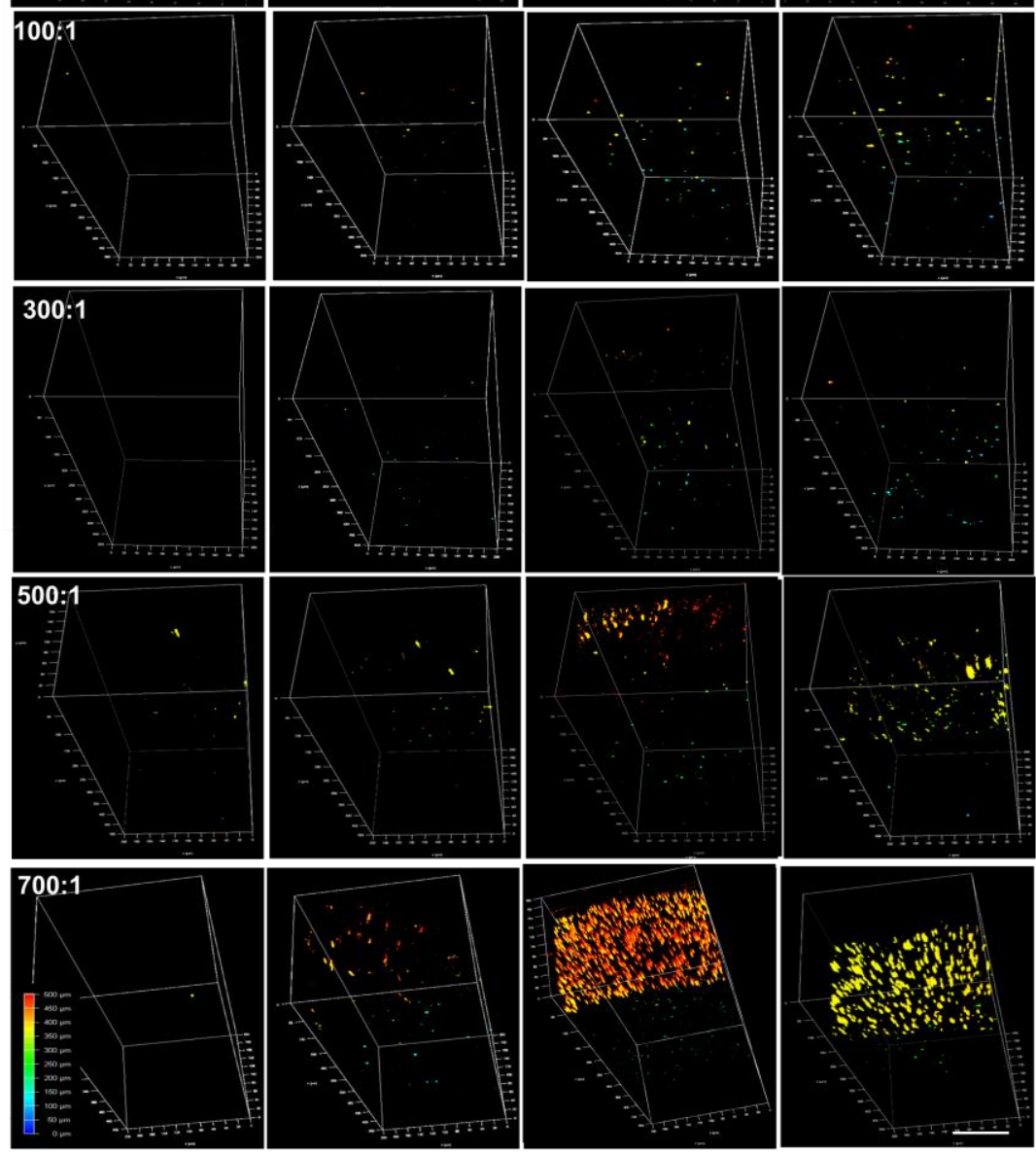

Figure 5. Confocal fluorescence image stacks of S.aureus interaction with PDMS control and PAAm hydrogels in the parallel flow chamber before PBS rinse (shear rate $=0.2 \mathrm{~s}^{-1}$ ) and after PBS rinse (shear rate $=10 \mathrm{~s}^{-1}$ ). Scales for PDMS and PAAm samples are $(200 \mu \mathrm{m} \times 200 \mu \mathrm{m} \times 35 \mu \mathrm{m})$ and $(200 \mu \mathrm{m} \times 200 \mu \mathrm{m} \times 500 \mu \mathrm{m}(\mathrm{x} \times \mathrm{y} \times \mathrm{z}))$ respectively. Color scale (bottom left) represents z-depth.

3.4 S.aureus interactions with PAAm ultrasoft hydrogels

\subsubsection{S.aureus deposition at PAAm interface}

Representative 3D reconstructed images show in situ S.aureus deposition up to $150 \mathrm{~min}$, followed by a 30min rinse with PBS (Figure 5). S.aureus in PBS buffer solution were primarily individual cells and 
nutrient-free media was used to delay bacterial growth. S.aureus deposition at the interface varied significantly with crosslinking. The increase in deposition over time is most noticeable for PAAm-500 and PAAm-700. PAAm-100 had negligible S.aureus deposition at the interface. PDMS served as a positive control because it is widely used in biomaterials (e.g. cochlear implants, soft contact lens and catheters) and its interactions with bacteria are well studied(52)(15). PDMS-based materials are known to have significant protein adsorption and bacterial interactions(53)(54).

The number of adherent S.aureus cells at PDMS and PAAm interfaces was quantified (Figure 6). For all samples, the initial deposition rate of S.aureus was linear with time before rinsing. This indicates that at the bacterial concentration and times tested here, competition between cells for the same adhesion site was not significant. PDMS had the most rapid increase in S.aureus deposition $\left(138 \mathrm{~cm}^{-2} \mathrm{~s}^{-1}\right)$. For PAAm, the increase in bacterial deposition lagged the start of adsorption on PDMS by $30 \mathrm{~min}$. This delay may be caused by the extended interaction time required for bacteria to approach the gel's fluid interface and substratum before engaging in irreversible adhesion (55). PAAm-700 had the highest initial rate of S.aureus deposition $\left(43.1 \mathrm{~cm}^{-2} \mathrm{~s}^{-1}\right)$, followed by PAAm-500 $\left(34.6 \mathrm{~cm}^{-2} \mathrm{~s}^{-1}\right)$, PAAm-300 $\left(20.4 \mathrm{~cm}^{-2} \mathrm{~s}^{-1}\right)$ and PAAm-100 $\left(0.583 \mathrm{~cm}^{-2} \mathrm{~s}^{-1}\right)$.

After deposition, loosely attached bacteria were removed by PBS rinsing (shear rate $=10 \mathrm{~s}^{-1}$ ). After $36330 \mathrm{~min}$ of flow, the PDMS surface had the highest S.aureus density, $(158 \pm 17) \times 10^{4} / \mathrm{cm}^{2}$. While bacteria 364 have been shown to adhere on some very soft hydrogels after rinsing, their ability to resist removal is 365 very weak (56)(57). In this work, when PAAm-500 and PAAm-300 were rinsed, bacterial density 366 decreased (from $(39 \pm 30) \times 10^{4} / \mathrm{cm}^{2}$ to $(23 \pm 21) \times 10^{4} / \mathrm{cm}^{2}$ for PAAm-500 and from $(24 \pm 21) \times 10^{4} / \mathrm{cm}^{2}$ to $367(13 \pm 22) \times 10^{4} / \mathrm{cm}^{2}$ for PAAm-300). PAAm-100, which had very little deposition to start out with ( 0.083X $\left.36810^{4} / \mathrm{cm}^{2}\right)$, did not have a significant change after rinsing. In contrast, PAAm-700 had a significant 369 increase in S.aureus density (from $(53 \pm 16)$ to $(93 \pm 20) \times 10^{4} / \mathrm{cm}^{2}$ ) after rinsing. This may be due to the physical properties of PAAm-700. Since it has the lowest G", the chains between the crosslinks are the most mobile and thus they are more easily displaced by impinging bacteria. Also reduced crosslinking 372 density leads to more imperfections such as free chain ends. Thus bacteria carried by the flow from 373 upstream are more likely to get caught in the gel where they are shielded in part from shear flow. 
A

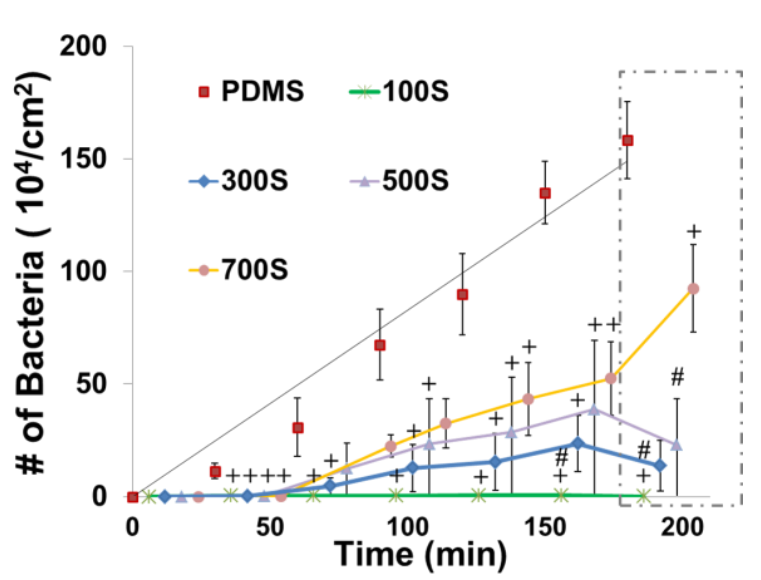

B

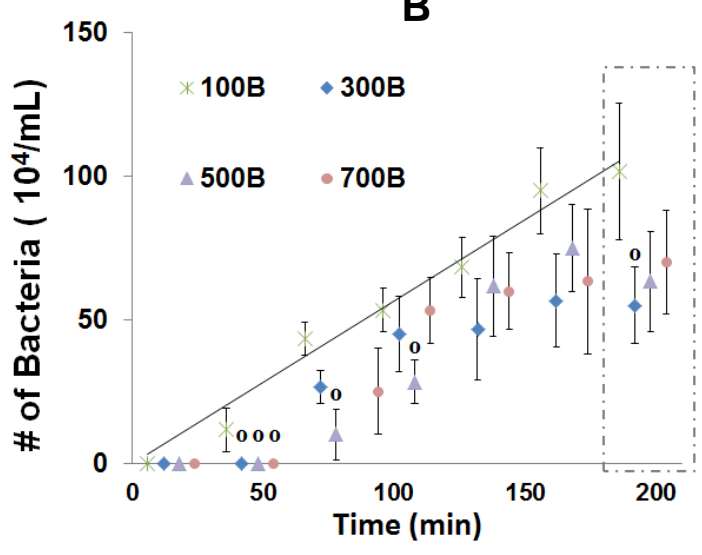

375 Figure 6. Number of S.aureus adhering at PAAm interface (A) and in PAAm bulk (B) in parallel flow chamber for

3763 3. Error bars represent the standard deviation over three different S.aureus cultures; ${ }^{+} p<0.05$ compared to 377 PDMS at the same time point; ${ }^{\#} p<0.05$ compared to PAAm-700 at the same time point; ${ }^{\circ} p<0.05$ compared to 378 PAAm-100 at the same time point. Data points in the dashed rectangle denote data collected after PBS wash.

\begin{tabular}{lllll}
\hline Material & $\begin{array}{l}\text { Stiffnes } \\
\mathrm{s}(\mathrm{kPa})\end{array}$ & Bacterial strains & $\begin{array}{l}\text { Culture } \\
\text { conditions }\end{array}$ & Effect on colonization
\end{tabular}$\quad$ Author

Alginate, chitosan, PVA-SbQ $1.6 \sim 38 \quad$ Pseudomonas sp.

rotating biofilm reactor with flow no direct correlation with stiffness

Rasmussen et al. (57) and agarose

$\begin{array}{lll} & & \text { Bacillus sp. and } \\ \text { Agarose } & 6.6- & \text { Pseudoalteromonas Static } \\ & 110 & s p .\end{array}$

$\begin{array}{llll}\text { PDMS } & 100 \sim & \text { E.coli and } P . & \text { Static } \\ \text { aeruginosa } & 2600 & \end{array}$

PEGDMA and soft agar

adhesion increased with stiffness

Kolewe et al.(58)

Table 2. Studies of how bulk soft hydrogel physicochemical properties affect bacterial adhesion and biofilm formation.

A number of theoretical models have been used to explain bacterial adhesion to surfaces. DLVO(Derjaguin-Landau-Verwey-Overbeek ) theory (59)describes van der Waals and electrostatic interactions between colloid particles and a surface. Thermodynamic approaches (60) assume reversible 
adhesion and account for interfacial interactions—such as van der Waals, acid-base, and dipole interactions-during the adhesion process. Extended models of both DLVO and thermodynamic approaches have been developed to better explain adhesion behaviors observed in bacterial systems. These models have been applied to explain some observations of studies on bacterial adhesion to hydrogels (Table 2), but not entirely successful in predicting various adhesion behaviors Rasmussen et al. investigated Pseudomonas sp.adhesion on different hydrogel materials in a rotating biofilm reactor. The authors did not find a consistent correlation between adhesion and macroscopic hydrophobicity, surface charge, or stiffness (57). The remaining studies listed in Table 2 found correlations between stiffness and adhesion depending on bacterial strain, material and experimental conditions. Kolewe et al. found that adhesion for both motile $E$. coli and relatively non-motile $S$. aureus increased with stiffness of PEGDMA and soft agar. In contrast, Song et al. found that adhesion of two motile bacteria (E.coli and $P$. aeruginosa) to PDMS decreased with increasing stiffness. Guegan et al. found that a strain with strong motility (Pseudoalteromonas sp. D41) adhered more strongly to stiffer agarose, whereas bacteria with weak motility (Bacillus sp. 4J6) adhered more strongly to agarose with lower elastic modulus. These studies demonstrated that bacterial properties (shape, membrane structure and motility) are important but not decisive for bacterial adhesion on hydrogels. The studies in Table 2 also show that the relationship between $\mathrm{G}^{\prime}$ and adhesion is often correlated for small ranges of $\mathrm{G}$ 'for hydrogel materials. Although hypotheses have been suggested for the non-monotonic relationship between adhesion and stiffness (57)(56), an overall unifying model has yet to be discovered.

For ultrasoft hydrogels, bacteria approaching the surface through a layer of highly viscous water adjacent. The PAAm gels tested here were soaked for 14 days to reach equilibrium. Considering the very high water content (>96\%) after fully swelling, the interfacial free energy at the gel-water interface is largely minimized (61). The minimum interfacial free energy hypothesis argues that when interfacial free energy at the interface is minimized, the reversibility of interaction between biological entities and the interface is likely increased. Bacterial interaction with such an interface would normally be unfavorable. This mechanism has been used to explain experimental observations on anti-fouling properties of neutral hydrogel coatings with low modulus, and is especially evident for PEG/PEO coatings. Like PAAm, PEG is a neutral, hydrophilic, linear synthetic polymer that shows excellent stability and solubility. Normally PEG coatings absorb large amount of water, forming a gel-like layer which has antifouling properties. Under flow conditions, the initial deposition of S.aureus on PEG brush coated silicone rubber was around $40 \times 10^{4} / \mathrm{cm}^{2}(62)$, comparable with deposition for PAAm-500 and PAAm-700 in the current study. Under these circumstances (relative to stiffer hydrogels), differences in bacterial strains (cell wall 
structure, motility, adhesion mechanisms, etc.) may play a greater role than material properties in the adhesion process. Environmental factors such as temperature, time of exposure and nutrients may also have more of an impact on the number of bacteria that adhere to hydrogels in the ultrasoft regime. These factors could explain why Guegan et al. found strain-dependent differences for adhesion on hydrogels closest to the ultrasoft range, whereas studies with stiffer materials showed no differences.

While this explanation helps us understand differences for ultrasoft hydrogels in general, it does not explain the specific trend seen in this work. If higher water content alone is responsible for unfavorable S. aureus interaction, why do we see an extremely large reduction of adhesion ( 4 orders of magnitude) from PAAm-700 to PAAm-100? We hypothesize that the interaction of bacterial cells with comparatively much softer PAAm under very slow flow rate may result in a situation where motility is dominated by viscous dissipation. Although S. aureus are larger than the pores in PAAm and steric hindrance impedes them from penetrating deeply into the network, they may become trapped in shallow depths of imperfections, loops and flexible chain segments that shelter them from shear flow and prevent further escape during rinsing.

\subsubsection{S.aureus interaction with PAAm bulk}

S.aureus were also observed within the bulk of the PAAm samples (Figure 5). The number of S.aureus inside all of the PAAm increased over 3h of deposition (Figure 6B). The final cell density in PAAm-100 was $102 \pm 23 \times 10^{4} / \mathrm{mL}$, in PAAm-300 was $55 \pm 13 \times 10^{4} / \mathrm{mL}$, in PAAm- 500 was $63 \pm 18 \times 10^{4} / \mathrm{mL}$, and in PAAm- 700 was $70 \pm 18 \times 10^{4} / \mathrm{mL}$. Infiltration in PAAm-100 started sooner than other materials and had the highest initial rate $\left(94.3 \mathrm{~mL}^{-1} \mathrm{~s}^{-1}\right)$. Infiltration increased at slower rates in PAAm-300 (55.1 $\left.\mathrm{mL}^{-1} \mathrm{~s}^{-1}\right)$, PAAm-500 $\left(58.5 \mathrm{~mL}^{-1} \mathrm{~s}^{-1}\right)$ and PAAm-700 $\left(59 \mathrm{~mL}^{-1} \mathrm{~s}^{-1}\right)$. Overall the infiltration to these three PAAms is not significantly different. We noticed during testing that PAAm-100 behaved differently than other PAAm during filling of crevices in the insert. PAAm-100 is not only the most crosslinked of the hydrogels, but also has modulus almost 500Pa more than the closest material PAAm-300, whose modulus is only about 150Pa more than PAAm-700. We hypothesized that as the hydrogels were injected through the syringe to fill the insert, some type of discontinuities formed in the materials. While the PAAm-300, 500 and 700 were able to self-seal these gaps, the more crosslinked PAAm-100 may have left discontinuities that could then be infiltrated by bacteria. Considering the unique morphological features identified with microscopy (Figure 3), and the fact that $S$. aureus are larger than the effective pore size of these PAAm, it is likely that the bacteria reached the crevices inside the stiffer gels through those discontinuities rather than through direct penetration of the bulk phase. 
The fact that bacteria may get into the bulk of dermal fillers through infiltration rather than penetration has not previously been studied in vitro, despite the fact that clinical samples show contamination of filler materials(63). Approximately 160 dermal filler products are available worldwide from more than 50 countries(10). The majority of them can be defined as gels because they either consist of cross-linked hydrogels (e.g. hyaluronic acid, polyacrylamide) or solid particles (e.g. calcium hydroxyapatite and PLLA) suspended in a carrier gel. Normally polyacrylamide gel products contain no particles, but some of the HA (hyaluronic acid) products are produced with a manufacturing process known as "sizing". The crosslinked HA is pushed through a specially sized screen and broken into particles ranging from $\sim 400$ to $\sim 1000 \mu \mathrm{m}(64)$. The results observed here point to the need for studies of the diffusion and spreading of solid particles or "sized" gel particles in dermal filler products. These manufacturing processes may increase the possibility of bacterial infiltration, especially for stiffer gels that cannot self-seal well.

$459 \quad$ 3.4.3 Biofilm formation

460 Biofilm formation has been shown to follow adhesion of pathogenic bacteria to medical device 461 materials (65)(66). To better understand the transformation of adherent bacteria on PAAm into biofilm 462 communities, we cultured the PAAm samples after bacterial deposition with nutrient for 24h with 463 minimal flow. Fluorescence image stacks taken at $24 \mathrm{~h}$ were reconstructed and analyzed (Figure 7) and 464 two properties of bacterial distribution were quantified (Table 3): interfacial coverage-the amount of 465 bacteria at the PAAm interface relative to the control interface; and bulk fraction-the fraction of bacteria 466 in the PAAm bulk relative to total bacteria of the sample. 
ide view
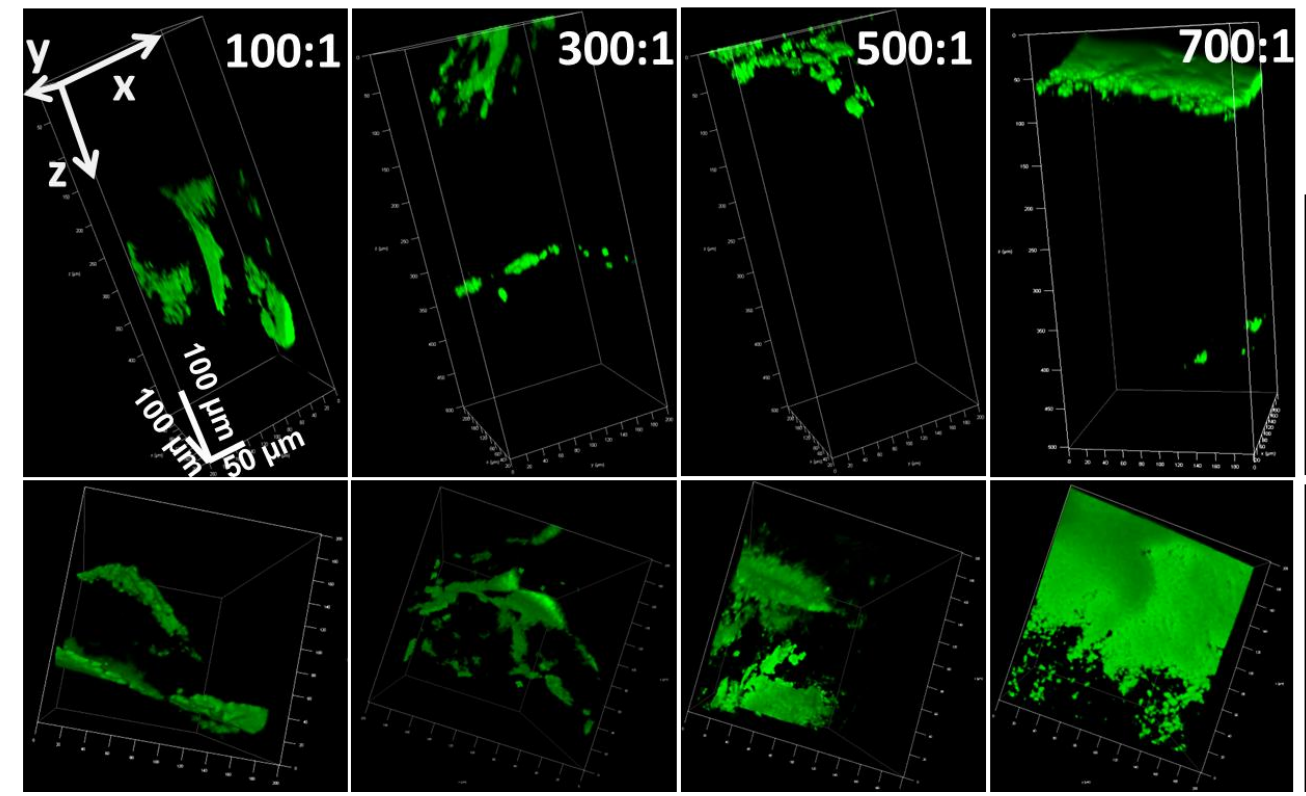

PDMS surface

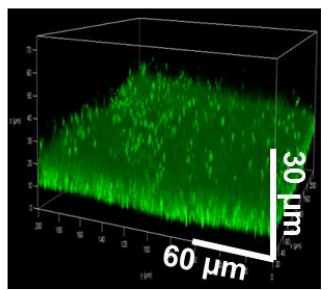

Figure 7. S. aureus biofilm formation in PAAm after 24h flow with nutrient medium. Side-view cube: $200 \mu \mathrm{m} x$ $200 \mu \mathrm{m} \times 500 \mu \mathrm{m}(\mathrm{x} \times \mathrm{y} \times \mathrm{z})$; Top-view square: $200 \mu \mathrm{m} \times 200 \mu \mathrm{m}(\mathrm{x} \times \mathrm{y})$; PDMS serves as a positive control (Side view: $(200 \mu \mathrm{m} \times 200 \mu \mathrm{m} \times 50 \mu \mathrm{m}(\mathrm{x} \times \mathrm{y} \times \mathrm{z}))$.

\begin{tabular}{llllll}
\hline Biofilm & $100: 1$ & $300: 1$ & $500: 1$ & $700: 1$ & PDMS \\
\hline Interfacial coverage (\%) & $2 \pm 1^{*}$ & $10 \pm 5^{*}$ & $31 \pm 18^{*}$ & $68 \pm 12^{*}$ & 100 \\
Bulk fraction (\%) & $100 \pm 0.04^{* *}$ & $62 \pm 20^{* *}$ & $48 \pm 21^{* *}$ & $34 \pm 13^{* *}$ & N/A \\
\hline
\end{tabular}

472 Table 3. Interfacial coverage (\% of positive control) and bulk volume percentage (\% of total) of biofilms from S.

473 aureus (COMSTAT analysis). \pm signs indicate standard deviations over three separately prepared S.aureus

474 cultures; *significant at $p<0.05 ;{ }^{* *}$ significant at $p<0.005$.

475 The trends observed were consistent with those seen in the deposition studies. The stiffest PAAm476100 had minimal bacterial growth at the interface, as seen in the calculated interfacial coverage of $4772 \pm 1 \%$. PAAm-100 exhibited significant elongated growth inside the bulk and had the highest percentage 478 of bacteria associated with the bulk phase ( $100 \pm 0 \%$ bulk fraction). The top view of the PAAm-100 (Figure

479 7) shows that bacterial distribution was non-uniform. When compared with the top view of other 480 materials, bacteria in PAAm-100 appeared to grow in flat sheets (compressed in one dimension). The 481 spatial distribution of $S$. aureus biofilm after $24 \mathrm{~h}$ provided additional insight on the infiltration of PAAm482100 observed in the adhesion data because it showed the limits of where the bacteria could grow within 483 the bulk of the injected material. Bacteria that infiltrate the PAAm-100 (reported in the adhesion study 484 above) most likely enter through discontinuous crevices-cracks or sheets-and are able to proliferate 
despite being over $100 \mu \mathrm{m}$ deep in the gel. While most pores are likely too small to allow significant bacterial penetration, they are large enough to support metabolic exchange of nutrients and wastes. Busscher et al.(67) speculated that because of the very weak interaction forces between bacteria and hydrogels, adhering bacteria may not "realize" they are on a surface. Such bacteria would not change their phenotype to form a biofilm with EPS encasing and could potentially stay in the "planktonic" regime of adhesion. In the present scenario, this may be the initial response of $S$. aureus that become entrapped in the PAAm. However, the longer-term outcome is likely influenced by the growth of bacteria in restricted dimensions where they will eventually come into contact with each other and begin to compress boundaries of the crevices in the gel. Guegan et al. (56) who studied hydrogels at the higher end of the ultrasoft range, identified proteins involved in key metabolic pathways and biofilm formation when bacteria adhered on ultrasoft hydrogels. Further investigation is needed to better understand the relationship between hydrogel stiffness and phenotypic changes in bacteria.

The non-trivial relationship between material properties and spatial distribution of bacterial biofilm growth (interface/bulk) has important implications for testing of ultrasoft materials and dermal fillers in particular. First, the biofilm distribution of the less crosslinked PAAm gels is similar to that of the nonporous control surface. This is consistent with the initial adhesion results and further confirms significantly different S.aureus interactions within a very small range of hydrogel stiffness $(17-654 \mathrm{~Pa})$. The most crosslinked PAAm-100 had very little bacteria at the interface after $24 \mathrm{~h}$, which would initially appear to demonstrate an advantage for stiffer dermal fillers. However, this advantage may be offset by the greater amount of bacteria that proliferates in the bulk of the PAAm-100. Unlike biofilm at the interface, which is readily accessible to immune surveillance and response, bacteria inside the filler bulk may not be easily accessible. Folds or cracks created in the stiffer gels during injection may form a unique microenvironmental niche for colonization and subsequent materials-associated infection.

508 The foreign body reaction (FBR) after biomaterials implantation is related to a series of cell-material 509 surface-mediated interactions(68). The infiltrating immune cells, such as macrophages are firstly 510 activated and attracted to various stimuli (chemokines, microbial products, immune complexes and certain extracellular proteins) from the provisional cell-material interface and tissue cells(69). It is reported both in vitro and in vivo that macrophages are able to probe their physical environment, although the mechanosensitive mechanism may be quite different from tissue cells(70)(71). Interestingly, PEG-coated surfaces were found enhancing phagocytosis rates as a consequence of reduced adhesion forces experienced by macrophages in a bacteria and macrophage co-culture model (72). Further studies are needed to demonstrate how the stiffness affects macrophage activities at the implant site and subsequent effects on the FBR. Also a co-culture model may be able to provide 
information on whether immune cells can surpass the water layer and infiltrate the polymer to reach bacteria in the crevices after injection. This is particularly related to our finding in the study. This may shed light on whether bacteria could be cleared in the FBR or an immune-privileged site may be created by the gel during subsequent fibroblastic reactions (i.e.granuloma)(73). 4. Conclusions

The goal of this work was to determine how material properties of ultrasoft medical devices such as dermal fillers might affect early stages of pathogenesis (adhesion and colonization). Although a variety of chemistries are used in dermal fillers, we synthesized and studied neutral PAAm hydrogels with several different crosslinking ratios to isolate the effects of mechanical differences. Changing the PAAm modulus from 17Pa to 654Pa resulted in a 4-log decrease in bacterial adhesion from $93 \times 10^{4} / \mathrm{cm}^{2}$ to $0.083 \times 10^{4} / \mathrm{cm}^{2}$. To put the magnitude of this difference in perspective with adhesion on stiffer materials, a 1-2 log reduction has often been reported as a significant breakthrough(74). These results are especially intriguing in light of recent reports about ultrasoft biomacromolecules (mucins) (75), which may play a role in reducing bacterial colonization via similar mechanisms seen here. The strategy of simulating hydrogel injection also helped to elucidate how the real-world use of injectable materials may be important for understanding pathogenesis. During the injection process, dermal filler material is extruded through the narrow bore of a syringe and the bulk shape is reconstituted in the tissue space. The shape of biofilm that grew in the fillers suggested that discontinuities formed in the stiffest, most highly crosslinked PAAm-100 during injection. We hypothesized that the higher degree of crosslinking in PAAm-100 does not allow gaps formed during injection to self-seal. Since the modulus of filler materials must be tailored for the location/depth of use, further research, esp. on chemical properties, is needed to understand how to minimize adhesion on the softest hydrogels and to minimize discontinuities in stiffer hydrogels. Research on self-healing hydrogels may provide significant insight on how to achieve this goal (76). Given the important role of material stiffness in response of mammalian cells, the insert could be used for co-culture studies of host integration or immune cell competition with bacteria on 542 ultrasoft materials.

\section{Disclaimer}

The mention of commercial products, their sources, or their use in connection with material reported herein is not to be construed as either an actual or implied endorsement of such products by the Department of Health and Human Services. The findings and conclusions in this article have not been formally disseminated by the U.S. Food and Drug Administration and should not be construed to represent any Agency determination or policy. 


\section{Acknowledgements}

This work was supported by the FDA Office of Women's Health. This project was supported in part by an appointment to the ORISE Research Participation Program at the CDRH, U.S. Food and Drug Administration, administered by the Oak Ridge Institute for Science and Education through an interagency agreement between the U.S. Department of Energy and FDA/CDRH.

\section{References}

1. Mayer M, Rabindranath R, Börner J, Hörner E, Bentz A, Salgado J, et al. Ultra-Soft PDMS-Based Magnetoactive Elastomers as Dynamic Cell Culture Substrata. PLoS ONE. 2013 Oct 18;8(10):e76196.

2. Zahouani H, Pailler-Mattei C, Sohm B, Vargiolu R, Cenizo V, Debret R. Characterization of the mechanical properties of a dermal equivalent compared with human skin in vivo by indentation and static friction tests. Skin Res Technol. 2009 Feb;15(1):68-76.

3. Nayar VT, Weiland JD, Nelson CS, Hodge AM. Elastic and viscoelastic characterization of agar. J Mech Behav Biomed Mater. 2012 Mar;7:60-8.

4. ASAPS. Cosmetic Surgery National Data Bank Statistics. The American Society for Aesthetic Plastic Surgery; 2014.

5. Christensen LH. Host Tissue Interaction, Fate, and Risks of Degradable and Nondegradable Gel Fillers. Dermatol Surg. 2009 Oct 1;35:1612-9.

6. Rohrich RJ, Monheit G, Nguyen AT, Brown SA, Fagien S. Soft-tissue filler complications: the important role of biofilms. Plast Reconstr Surg. 2010 Apr;125(4):1250-6.

7. DeLorenzi C. Complications of injectable fillers, part I. Aesthetic Surg J Am Soc Aesthetic Plast Surg. 2013 May;33(4):561-75.

8. Glogau RG, Kane M a. C. Effect of Injection Techniques on the Rate of Local Adverse Events in Patients Implanted with Nonanimal Hyaluronic Acid Gel Dermal Fillers. Dermatol Surg. 2008 Jun 1;34:S105-9.

9. Christensen L, Breiting V, Bjarnsholt $\mathrm{T}$, Eickhardt $\mathrm{S}, \mathrm{H} \emptyset$ gdall $\mathrm{E}$, Janssen $\mathrm{M}$, et al. Bacterial infection as a likely cause of adverse reactions to polyacrylamide hydrogel fillers in cosmetic surgery. Clin Infect Dis Off Publ Infect Dis Soc Am. 2013 May;56(10):1438-44.

10. Funt D, Pavicic T. Dermal fillers in aesthetics: an overview of adverse events and treatment approaches. Clin Cosmet Investig Dermatol. 2013 Dec 12;6:295-316.

11. Gladstone HB, Cohen JL. Adverse effects when injecting facial fillers. Semin Cutan Med Surg. 2007 Mar;26(1):34-9. 
12. El-Khalawany M, Fawzy S, Saied A, Al Said M, Amer A, Eassa B. Dermal filler complications: a clinicopathologic study with a spectrum of histologic reaction patterns. Ann Diagn Pathol. 2015 Feb;19(1):10-5.

13. Rish A. Polyacrylamide gel 10 years experience: with particular reference to complications from filling of the body of the lip. J Cosmet Dermatol. 2014 Dec;13(4):253-60.

14. Tuson HH, Weibel DB. Bacteria-surface interactions. Soft Matter. 2013 Apr 2;9(17):4368-80.

15. Willcox MDP, Harmis N, Cowell BA, Williams T, Holden BA. Bacterial interactions with contact lenses; effects of lens material, lens wear and microbial physiology. Biomaterials. 2001 Dec;22(24):3235-47.

16. Alhede M, Er O, Eickhardt S, Kragh K, Alhede M, Christensen LD, et al. Bacterial biofilm formation and treatment in soft tissue fillers. Pathog Dis. 2014 Apr;70(3):339-46.

17. Britt MR, Garibaldi RA, Wilfert JN, Smith CB. In Vitro Activity of Tobramycin and Gentamicin. Antimicrob Agents Chemother. 1972 Sep;2(3):236-41.

18. Santoro S, Russo L, Argenzio V, Borzacchiello A. Rheological properties of cross-linked hyaluronic acid dermal fillers. J Appl Biomater Biomech JABB. 2011 Aug;9(2):127-36.

19. Muntz A, Subbaraman LN, Sorbara L, Jones L. Tear exchange and contact lenses: A review. J Optom. 2015 Jan;8(1):2-11.

20. Lee J, Tae G, Kim YH, Park IS, Kim S-H, Kim SH. The effect of gelatin incorporation into electrospun poly(l-lactide-co- $\varepsilon$-caprolactone) fibers on mechanical properties and cytocompatibility. Biomaterials. 2008 Apr;29(12):1872-9.

21. Chiu C-T, Lee J-S, Chu C-S, Chang Y-P, Wang Y-J. Development of two alginate-based wound dressings. J Mater Sci Mater Med. 2008 Jun;19(6):2503-13.

22. Affatato S. Wear of Orthopaedic Implants and Artificial Joints. Elsevier; 2012. 449 p.

23. Brandon $\mathrm{H}$, Jerina $\mathrm{K}$, Wolf $\mathrm{C}$, Young $\mathrm{V}$. Ultimate strength properties of explanted and control Silastic II silicone gel-filled breast implant shells. Aesthet Surg J. 2000 Mar;20(2):122-32.

24. Fisher LE, Hook AL, Ashraf W, Yousef A, Barrett DA, Scurr DJ, et al. Biomaterial modification of urinary catheters with antimicrobials to give long-term broadspectrum antibiofilm activity. J Controlled Release. 2015 Mar;202:57-64.

25. Dong $\mathrm{H}$, Walker $\mathrm{GM}$. Adjustable stiffness tubes via thermal modulation of a low melting point polymer. Smart Mater Struct. 2012;21(4):042001.

26. Tuson HH, Auer GK, Renner LD, Hasebe M, Tropini C, Salick M, et al. Measuring the stiffness of bacterial cells from growth rates in hydrogels of tunable elasticity. Mol Microbiol. 2012 Jun;84(5):874-91.

614 27. Salamone JC. Polymeric Materials Encyclopedia, Twelve Volume Set. CRC Press; 1996. 616 p. 
28. Zhou M, Smith AM, Das AK, Hodson NW, Collins RF, Ulijn RV, et al. Self-assembled peptide-based hydrogels as scaffolds for anchorage-dependent cells. Biomaterials. 2009 May;30(13):2523-30.

29. Valentine MT, Kaplan PD, Thota D, Crocker JC, Gisler T, Prud'homme RK, et al. Investigating the microenvironments of inhomogeneous soft materials with multiple particle tracking. Phys RevE. 2001 Dec;64(6):061506.

30. Petersen J. Polyacrylamide hydrogel as a soft tissue filler endoprosthesis [Internet]. US20050175704 A1, 2005 [cited 2015 Jul 28]. Available from: http://www.google.com/patents/US20050175704

31. Lin C-C, Metters AT. Hydrogels in controlled release formulations: Network design and mathematical modeling. Adv Drug Deliv Rev. 2006 Nov 30;58(12-13):1379-408.

32. Flory PJ. Principles of Polymer Chemistry. Ithaca, NY: Cornell University Press; 1953.688 p. (The George Fisher Baker Non-Resident Lectureship in Chemistry at Cornell University).

33. Ding ZY, Aklonis JJ, Salovey R. Model filled polymers. VI. Determination of the crosslink density of polymeric beads by swelling. J Polym Sci Part B Polym Phys. 1991 Jul 1;29(8):1035-8.

34. Canal T, Peppas NA. Correlation between mesh size and equilibrium degree of swelling of polymeric networks. J Biomed Mater Res. 1989 Oct;23(10):1183-93.

35. Niamlang S, Buranut T, Niansiri A, Sirivat A. Controlled Aloin Release from Crosslinked Polyacrylamide Hydrogels: Effects of Mesh Size, Electric Field Strength and a Conductive Polymer. Mater 1996-1944. 2013 Oct;6(10):4787-800.

36. Schindelin J, Arganda-Carreras I, Frise E, Kaynig V, Longair M, Pietzsch T, et al. Fiji: an open-source platform for biological-image analysis. Nat Methods. $2012 \mathrm{Jul} ; 9(7): 676-82$.

37. Heydorn A, Nielsen AT, Hentzer M, Sternberg C, Givskov M, Ersbøll BK, et al. Quantification of biofilm structures by the novel computer program COMSTAT. Microbiol Read Engl. 2000 Oct;146 ( Pt 10):2395-407.

38. Holt B, Tripathi A, Morgan J. Viscoelastic Response of Human Skin to Low Magnitude Physiologically Relevant Shear. J Biomech. 2008 Aug 28;41(12):2689-95.

39. Holmes DL, Stellwagen NC. Estimation of polyacrylamide gel pore size from Ferguson plots of linear DNA fragments. II. Comparison of gels with different crosslinker concentrations, added agarose and added linear polyacrylamide. Electrophoresis. 1991 Sep;12(9):612-9.

40. Stellwagen NC. Apparent pore size of polyacrylamide gels: comparison of gels cast and run in Trisacetate-EDTA and Tris-borate-EDTA buffers. Electrophoresis. 1998 Jul;19(10):1542-7.

41. Flory PJ, Jr JR. Statistical Mechanics of Cross-Linked Polymer Networks I. Rubberlike Elasticity. J Chem Phys. 1943 Nov 1;11(11):512-20.

42. Monteiro JM, Fernandes PB, Vaz F, Pereira AR, Tavares AC, Ferreira MT, et al. Cell shape dynamics during the staphylococcal cell cycle. Nat Commun. 2015 Aug 17;6:8055. 
43. Wang $\mathrm{Y}$, da Silva Domingues JF, Subbiahdoss G, van der Mei HC, Busscher HJ, Libera M. Conditions of lateral surface confinement that promote tissue-cell integration and inhibit biofilm growth. Biomaterials. 2014 Jul;35(21):5446-52.

44. Sunyer R, Jin AJ, Nossal R, Sackett DL. Fabrication of Hydrogels with Steep Stiffness Gradients for Studying Cell Mechanical Response. PLoS ONE. 2012 Oct 4;7(10):e46107.

45. Byron ML, Variano EA. Refractive-index-matched hydrogel materials for measuring flow-structure interactions. Exp Fluids. 2013 Jan 20;54(2):1-6.

46. Whitehead KA, Colligon J, Verran J. Retention of microbial cells in substratum surface features of micrometer and sub-micrometer dimensions. 2005;41(2-3):129-38.

47. Boyd RD, Verran J, Jones MV, Bhakoo M. Use of the Atomic Force Microscope To Determine the Effect of Substratum Surface Topography on Bacterial Adhesion. Langmuir. 2002 Mar $1 ; 18(6): 2343-6$.

48. Jesus M, Yebra-Pimentel E. Hydrogel Contact Lenses Surface Roughness and Bacterial Adhesion. In: Adio A, editor. Ocular Diseases [Internet]. InTech; 2012 [cited 2015 Oct 7]. Available from: http://www.intechopen.com/books/ocular-diseases/hydrogel-contact-lenses-surface-roughnessand-bacterial-adhesion

49. Perera-Costa D, Bruque JM, González-Martín ML, Gómez-García AC, Vadillo-Rodríguez V. Studying the Influence of Surface Topography on Bacterial Adhesion using Spatially Organized Microtopographic Surface Patterns. Langmuir. 2014 Apr 29;30(16):4633-41.

50. Stoodley P, Hall-Stoodley L, Lappin-Scott HM. Detachment, surface migration, and other dynamic behavior in bacterial biofilms revealed by digital time-lapse imaging. Microb Growth Biofilms Pt B. 2001;337:306-18.

51. Busscher HJ, Mei HC van der. Microbial Adhesion in Flow Displacement Systems. Clin Microbiol Rev. 2006 Jan 1;19(1):127-41.

52. Song F, Ren D. Stiffness of Cross-Linked Poly(Dimethylsiloxane) Affects Bacterial Adhesion and Antibiotic Susceptibility of Attached Cells. Langmuir. 2014 Sep 2;30(34):10354-62.

53. Regehr KJ, Domenech M, Koepsel JT, Carver KC, Ellison-Zelski SJ, Murphy WL, et al. Biological implications of polydimethylsiloxane-based microfluidic cell culture. Lab Chip. 2009 Aug 7;9(15):2132-9.

54. Phillips KS, Cheng Q. Microfluidic Immunoassay for Bacterial Toxins with Supported Phospholipid Bilayer Membranes on Poly(dimethylsiloxane). Anal Chem. 2005 Jan 1;77(1):327-34.

55. Savage DC, Fletcher M. Bacterial Adhesion: Mechanisms and Physiological Significance. Springer; 1985. $504 \mathrm{p}$.

56. Guégan C, Garderes J, Le Pennec G, Gaillard F, Fay F, Linossier I, et al. Alteration of bacterial adhesion induced by the substrate stiffness. Colloids Surf B Biointerfaces. 2014 Feb 1;114:193200. 
57. Rasmussen K, Østgaard K. Adhesion of the marine bacterium Pseudomonas sp. NCIMB 2021 to different hydrogel surfaces. Water Res. 2003 Feb;37(3):519-24.

58. Kolewe KW, Peyton SR, Schiffman JD. Fewer Bacteria Adhere to Softer Hydrogels. ACS Appl Mater Interfaces. 2015 Sep 9;7(35):19562-9.

59. Derjaguin B. A theory of interaction of particles in presence of electric double-layers and the stability of lyophobe colloids and disperse systems. 1939;10:333-46.

60. Morra M, Cassinelli C. Bacterial adhesion to polymer surfaces: a critical review of surface thermodynamic approaches. J Biomater Sci Polym Ed. 1997;9(1):55-74.

61. King RN, Andrade JD, Ma SM, Gregonis DE, Brostrom LR. Interfacial tensions at acrylic hydrogelwater interfaces. J Colloid Interface Sci. 1985 Jan;103(1):62-75.

62. Nejadnik MR, van der Mei HC, Norde W, Busscher HJ. Bacterial adhesion and growth on a polymer brush-coating. Biomaterials. 2008 Oct;29(30):4117-21.

63. Van Dyke S, Hays GP, Caglia AE, Caglia M. Severe Acute Local Reactions to a Hyaluronic Acidderived Dermal Filler. J Clin Aesthetic Dermatol. 2010 May;3(5):32-5.

64. Attenello NH, Maas CS. Injectable fillers: review of material and properties. Facial Plast Surg FPS. 2015 Feb;31(1):29-34.

65. Donlan RM. Biofilm Formation: A Clinically Relevant Microbiological Process. Clin Infect Dis. 2001 Oct 15;33(8):1387-92.

66. Bryers JD. Medical Biofilms. Biotechnol Bioeng. 2008 May 1;100(1):1-18.

67. Busscher HJ, Mei HC van der. How Do Bacteria Know They Are on a Surface and Regulate Their Response to an Adhering State? PLOS Pathog. 2012 Jan 26;8(1):e1002440.

68. Anderson JM, Rodriguez A, Chang DT. FOREIGN BODY REACTION TO BIOMATERIALS. Semin Immunol. 2008 Apr;20(2):86-100.

69. Nilsson B, Ekdahl KN, Mollnes TE, Lambris JD. The role of complement in biomaterial-induced inflammation. Mol Immunol. 2007 Jan;44(1-3):82-94.

70. Féréol S, Fodil R, Labat B, Galiacy S, Laurent VM, Louis B, et al. Sensitivity of alveolar macrophages to substrate mechanical and adhesive properties. Cell Motil Cytoskeleton. 2006 Jun;63(6):321-40.

71. Blakney AK, Swartzlander MD, Bryant SJ. The effects of substrate stiffness on the in vitro activation of macrophages and in vivo host response to poly(ethylene glycol)-based hydrogels. J Biomed Mater Res A. 2012 Jun;100(6):1375-86.

72. da Silva Domingues JF, Roest S, Wang Y, van der Mei HC, Libera M, van Kooten TG, et al. Macrophage phagocytic activity toward adhering staphylococci on cationic and patterned hydrogel coatings versus common biomaterials. Acta Biomater. 2015 May;18:1-8. 
73. Styperek A, Bayers S, Beer M, Beer K. Nonmedical-grade Injections of Permanent Fillers. J Clin Aesthetic Dermatol. 2013 Apr;6(4):22-9.

74. Cheng G, Zhang Z, Chen S, Bryers JD, Jiang S. Inhibition of bacterial adhesion and biofilm formation on zwitterionic surfaces. Biomaterials. 2007 Oct;28(29):4192-9.

75. Caldara M, Friedlander RS, Kavanaugh NL, Aizenberg J, Foster KR, Ribbeck K. Mucin Biopolymers Prevent Bacterial Aggregation by Retaining Cells in the Free-Swimming State. Curr Biol. 2012 Dec 18;22(24):2325-30.

76. Fang $\mathrm{Y}$, Wang C-F, Zhang Z-H, Shao H, Chen S. Robust Self-Healing Hydrogels Assisted by CrossLinked Nanofiber Networks. Sci Rep [Internet]. 2013 Oct 3 [cited 2016 Apr 2];3. Available from: http://www.ncbi.nlm.nih.gov/pmc/articles/PMC3789405/ 